\title{
A glacial survivor of the alpine Mediterranean region: phylogenetic and phylogeographic insights into Silene ciliata Pourr. (Caryophyllaceae)
}

Ifigeneia Kyrkou, José María Iriondo, Alfredo García-Fernández

Silene ciliata Pourr. (Caryophyllaceae) is a species with a highly disjunct distribution which inhabits the alpine mountains of the Mediterranean Basin. We investigated the phylogeny and phylogeography of the species to a) clarify the long- suggested division of $S$. ciliata into two subspecies, b) evaluate its phylogenetic origin and c) assess whether the species' diversification patterns were affected by the Mediterranean relief. For this purpose, we collected DNA from 25 populations of the species that inhabit the mountains of Portugal, Spain, France, Italy, former Yugoslav Republic of Macedonia, Bulgaria and Greece and studied the plastid regions $r b c L, r p s 16$ and trnL. Major intraspecific variation was supported by all analyses, while the possibility of the existence of more varieties or subspecies was not favoured. Plastid DNA (cpDNA) evidence was in accordance with the division of $S$. ciliata into the two subspecies, one spreading west (Iberian Peninsula and Central Massif) and the other east of the Alps region (Italian and Balkan Peninsula). This study proposes that the species' geographically disconnected distribution has probably derived from vicariance processes and from the Alps acting as a barrier to the species' dispersal. The monophyletic origin of the species is highly supported. cpDNA patterns were shown independent of the chromosome evolution in the populations and could have resulted from a combination of geographic factors providing links and barriers, climatic adversities and evolutionary processes that took place during Quaternary glaciations. 
1 Authors: Ifigeneia Kyrkou ${ }^{1,2}$, José María Iriondo ${ }^{2} \&$ Alfredo García-Fernández ${ }^{2}$

2

3

4 Affiliations:

$5 \quad{ }^{1}$ Dept. of Biotechnology, Agricultural University of Athens. Iera Odos 75, 11855, Athens,

6 Greece

$7 \quad{ }^{2}$ Area de Biodiversidad y Conservación, Universidad Rey Juan Carlos. c/ Tulipán s/n,

8 28933, Móstoles, Madrid, Spain

9

10

corresponding author: Ifigeneia Kyrkou, address: Thyateiron 9, 17121, Athens, Greece,

11

email: ifigeneia.kyrkou@gmail.com, phone number: (+30)6972594778

12 


\section{Introduction}

Alpine environments provide interesting frameworks for answering phylogeographic and phylogenetic questions that remain unresolved from a botanical perspective. Plant species in mountain ecosystems face challenges for survival and adaptation to different environmental conditions and fluctuations (Körner, 2003). High altitude habitats often follow an island-like structure due to significant levels of isolation and fragmentation (Pawłowski, 1970), thus leading to adaptive divergence and, finally, speciation events (Wiens, 2004). These inland habitat patches could harbour greater species diversity compared to a seamless area of the same extent (Quinn \& Harrison, 1988). Nunataks and peripheral glacial refugia inside mountain ranges are thought to have sheltered a wide range of biological and genetic diversity during the Pleistocene glacial-interglacial periods (Hewitt, 2000; Taberlet et al., 1998).

floristic taxa of the Alps (Schönswetter et al., 2005), while the rest of the European mountain ranges and the processes occurring inside them during glaciations have generally been overlooked (Hewitt, 2001). Nevertheless, interest in Mediterranean mountain systems has gradually been increasing (e.g. Vargas, 2003; Mas de Xaxars et al., 2015). The Mediterranean Basin has undoubtedly played a crucial role in shaping the genetic and distributional patterns of many species, since it provided them with sanctuary during glaciations (Médail \& Diadema, 2009) and served as a starting point for the recolonization of northern latitudes (Petit et al., 2003; Tzedakis et al., 2002). Indeed, the Southern Mediterranean Peninsulas (i.e. Iberian, Italian and Balkan) are considered important glacial refugia for many plant and animal species (e.g. Taberlet et al., 1998; Hewitt 2000; Hewitt, 2004), and Mediterranean mountains have been considered potential refugia for alpine 62 plants (Vargas, 2003; Hughes, Woodward \& Gibbard, 2006). 
Silene L. is a genus that has caught the attention of many scientists due to its many interesting attributes, making it a potential "model system" in ecology and evolution (Bernasconi et al., 2009). Yet, its phylogeny still remains perplexing and unclear (Oxelman et al., 2000; Greenberg \& Donoghue, 2011). Half of Silene species inhabit the Mediterranean Basin (Greuter, 1995) and c. 87 of them are found in altitudes above the treeline (based on Jalas \& Suominen, 1988 and supported by Zángheri \& Brilli-Cattarini, 1976; Castroviejo et al., 1986-2001; Strid \& Tan, 2002). The majority of Silene species are diploid with $2 n=20$ or $2 n=24$ (Bari, 1973). The latest taxonomic classification can be found in Greenberg \& Donoghue (2011). Many recent studies have tried to clarify the phylogeny of its tribes and sections (e.g. Oxelman et al., 2000; Rautenberg et al., 2008; Rautenberg et al., 2010).

Although Silene species in alpine environments have been included in phylogenetic and phylogeographic studies of the genus Silene (e.g. Abbott et al., 1995; Popp et al., 2005), those native to Mediterranean mountains have been understudied. Silene ciliata is a notable species in the genus Silene, because it presents a circum-mediterranean distribution around mountain ranges and above the treeline. Taxonomists have consistently divided it into two subspecies based on habit differences and disjunct geographical distribution. These are $S$. ciliata subsp. graefferi (referred to as the "Italian race"), which is principally found in the Italian and the Balkan Peninsula, and S. ciliata subsp. ciliata, (referred to as the "Spanish race"), which occupies the Iberian Peninsula (Blackburn, 1933). Blackburn (1933) recorded large morphological and cytological variation both between and within the two races. She concluded that the prime differences inside the "Italian race" are size, leaf form, hairiness and flower colour, whereas variation in the "Spanish race" is unravelled in all features of the plant. For the western populations several other subspecies or varieties have long been proposed (e.g. Silene ciliata subsp arvatica Lag. in Varied .Ci. (1805), Silene ciliata subsp. elegans (Link. ex Brot.) Rivas Martínez in Brotero, 1804), although the validation of these subcategories remains unsolved with available taxonomical data (Nieto Feliner, 1985). This species also stands out for its extraordinary variability of ploidy levels in natural populations (i.e., $2 \mathrm{n}=24,36,48,72,84,96,120,144,168,192,240$; Blackburn, 1933; Küpfer, 1974). In particular, subsp. ciliata is reported to vary from 
94 95

diploid to 20-ploid complements, whereas in subsp. graefferi only diploid and tetraploid plants are described (Blackburn, 1933; Küpfer, 1974; Tutin et al., 1995).

We followed a phylogenetic and phylogeographic approach to this species to gain insight into the diversification processes that have taken place in alpine environments of Mediterranean high mountains. To our knowledge, this is the first study to cover the vast majority of the alpine Mediterranean area with the aid of molecular marker evidence. We hypothesize that: 1) in spite of its heterogeneity discussed by Blackburn in 1933, the species is of monophyletic origin; 2) this heterogeneity is reflected in great cpDNA diversification that could explain the sub-classification of this species into two distinct subspecies as proposed by Blackburn (1933) and maintained by Tutin et al. (1995) and; 3) differentiation patterns are essentially determined by the geomorphology and spatial location of the Mediterranean mountain ranges.

\section{Material and Methods}

Studied species

Silene ciliata Pourr. (subsect. Fruticulosae, Caryophyllaceae) is endemic to Europe and inhabits the main Mediterranean mountain ranges in the northern half of Mediterranean Basin countries spreading along the Iberian Peninsula, the Central Massif, the Apennines and the Balkan Peninsula (Tutin et al., 1995). It is an alpine, chamaephytic, perennial, cushion plant, which typically forms pulviniform rosettes of up to $2 \mathrm{~cm}$ in height and 15 $\mathrm{cm}$ in diameter with high variability in size. Each plant has an average of $13 \pm 11 \mathrm{~cm}$ (mean $\pm \mathrm{SD}$ ) flowering stems that reach $15 \mathrm{~cm}$ in height and bear 1-5 flowers (GiménezBenavides, Escudero \& Iriondo, 2007).

\section{Taxon selection}

Twenty-five specimens of $S$. ciliata populations covering the species distribution range were sampled for this study (Fig. 1). Plant material was obtained from herbarium specimens or directly from the field and stored as silica gel-dried material (Table 1). All 
126 field studies carried out by the authors were conducted with the permission of "Junta de

127 Castilla y León” and "Comunidad de Madrid” (approval code numbers: 20144360000894

128 and 10/117476.9/14, respectively). To assess possible intrapopulation cpDNA variation,

129 DNA from four additional individuals of the Cen3 population was also extracted and

130 amplified.

131 For the estimation of the phylogeny of the polymorphic cpDNA region, eight

132 additional species of genus Silene, phylogenetically close to Silene ciliata, were included

133 in the study. The selection of these species was based on the most recent phylogenetic

134 studies of Sileneae (Sloan et al., 2009; Greenberg \& Donoghue, 2011) and the availability

135 of the required polymorphic cpDNA regions. The search was performed in GenBank

136 sequence database, and the species selected as outgroups were S. latifolia Poiret, $S$.

137 uniflora Roth, S. vulgaris (Moench) Garcke and -phylogenetically closer to S. ciliata- S.

138 acaulis (L.) Jacq, S. otites (L.) Wibel, S. nutans L., S. paradoxa L. and S. schafta S. G.

139 Gmel. ex Hohen. Although S. borderei Jordan and S. legionensis Lag. are classified in the

140 same section as $S$. ciliata in recent Floras (e.g., Flora Europaea, Tutin et al. 1995; Flora

141 Iberica; Castroviejo et al. 1986), we did not consider them because they are not included in

142 the phylogenetic study of Sileneae by Greenberg \& Donoghue (2011). The accession

143 numbers of all outgroup regions are listed in Table S3.

DNA markers

In this phylogenetic and phylogeographic approach, we chose maternally inherited plastid DNA (hereafter cpDNA) as the focus of our study, since it provides a conservative and enduring record of plant migrational spread (McCauley, 1997; Irwin, 2002) compared to biparentally inherited nuclear markers that show recombination (Petit, Kremer \& Wagner, 1993; Heuertz et al., 2004).

Each of the 25 extracted DNA samples was amplified for the $r b c L, r p s 16$ and $\operatorname{trnL}$ polymorphic cpDNA regions. These regions were selected from the 12 regions that had previously shown major variation and the best amplification profile (Shaw et al., 2005; Shaw et al., 2007). 
DNA extraction and amplification

158

159

160

For DNA extraction, approximately $20 \mathrm{mg}$ of dried leaf tissue of each plant sample were weighed. Extractions were performed following the protocol of Qiagen Plant DNA extraction kit (QIAGEN Inc., CA, USA) with some modifications. The primers used and the PCR conditions applied for each marker, as well as the primer sequences and references, are listed in Table S2. The PCR mix was prepared using PureTaq Ready-To-Go PCR beads (GE Healthcare, Uppsala, Sweden).

Data analyses

Sequencing results were evaluated and corrected manually before being subjected to multiple alignment. The manual corrections were made to check whether the differences found among some bases of the sequences were unique/repeated in some of the sequences and to ensure the presence of gaps. Contigs were assembled and edited with Sequencher 4.1.4 (Gene Codes Corp., MI, USA), Bioedit (Hall, 1999) and ClustalW (Thompson, Higgins \& Gibson, 1994). In the latter, default settings were used.

The number of variation and informative sites of our aligned sequences was determined using DnaSP v.5.10.01 (Librado \& Rozas, 2009). The phylogenetic analyses were performed using two different statistical approaches ("Bayesian inference" and "Maximum likelihood") for verification reasons. In the Bayesian analysis, sequence data were first introduced to jModeltest (Posada, 2008) to determine the best fitting evolutionary model according to the AIC criterion. This process was followed to generate a dendrogram for each polymorphic cpDNA region, plus one dendrogram that included all polymorphic cpDNA regions together. The suggested model for $r b c L$ was [HKY], for $\operatorname{rps} 16[\mathrm{GTR}+\mathrm{G}]$, for $\operatorname{trn} L[\mathrm{HKY}+\mathrm{I}]$ and for the tree including all markers [GTR+ G]. These models were then inserted into MrBayes 3.1.2 (Huelsenbeck et al., 2001) and posterior probabilities (hereafter PP) were estimated using the Markov chain Monte Carlo (MCMC) method. Four Markov chains were run in parallel for 10,000,000 generations and sampled every 100 generations. The first 100 generations were set as the "burn-in" period, while the rest were used to calculate the $50 \%$ majority rule consensus phylogeny and 
posterior probability. The resulting dendrogram archives were revised with FigTree v. 1.3.1 (Rambaut, 2006). A maximum likelihood dendrogram including all the polymorphic cpDNA regions together was also generated with PhyML 3.0 (Guindon et al., 2010) under the same evolutionary model used for the Bayesian analysis. The reliability of the branches was calculated through bootstrapping, after producing 1000 bootstrapped data sets. All outputs were compared and analysed to infer the evolutionary history of our study species.

Next, each group of polymorphic cpDNA region sequences was analysed with TCS 1.2.1 (Clement, Posada \& Crandall, 2000) and classified according to statistically parsimonious haplotype groups. The haplotype groups were linked by the program, constructing a network of mutation steps, which visualized the genetic distance between them. For the construction of the haplotype networks, deletions were not treated as polymorphic sites, while the analysis was performed under the default of $95 \%$ connection limit. To facilitate interpretation, a total cpDNA haplotype network was created with this method. In addition, haplotype networks of $r b c L, \operatorname{rps} 16$ and $\operatorname{trn} L$ regions were obtained separately to check the congruence between markers. Likewise, total neighbour-net analysis network including all three cpDNA regions together was also designed using Splits Tree v. 4.13.1 (Huson \& Bryant, 2006) and following the uncorrected p-distance between individuals. The support for each branch was tested using the bootstrapping method with 1000 replicates. One final test was performed with the Bayesian Analysis of Population Structure 6 (BAPS, Corander et al., 2008). This Bayesian approach is conditioned on the geographical sampling information available. The actual analysis is performed using a systematic hierarchical Bayesian approach, where a Markov chain Monte Carlo (MCMC) estimation is used whenever the number of possible partitions is too large to be handled with exact calculations. We chose BAPS software to infer the best genetic structure, considering the coordinates of each sample, and ran a test of spatial clustering of individuals, with five replicates for each possible number of groups $(K)$.

\section{Results}

Chloroplast haplotype and intrapopulation variation 
220

221

222

223

224

225

226

227

228

229

230

231

232

233

234

235

236

237

238

239

240

241

242

243

244

245

After multiple alignment evaluation of the three polymorphic cpDNA regions, the final length of the study region resulted in 564 nucleotides for $r b c L, 756$ nucleotides for $r p s 16$ and 509 nucleotides for trnL. Thus, the length of the combined matrix of an "all-marker" region was 1829 nucleotides. The number of variable sites among chloroplast markers ranged from 4 to 25, while that of parsimony informative sites ranged from 3 to 16 (Table 2). Sequences were submitted to GenBank (accession numbers are available in Table S4).

The intrapopulation study showed no divergence for $r b c L$ and inconsistent polymorphisms (i.e., only present in one individual and probably associated to sequencing errors) in one and two bases for rps 16 and $\operatorname{trn} L$, respectively. Therefore, we considered that the evidence for intrapopulation variation was not strong enough to require further testing.

Phylogeny, genetic distance analyses and population structure

No incongruence in results was found among the single markers. Therefore, we essentially used a combined study because all the markers are in the chloroplast genome. The resulting “all-marker" dendrogram from the Bayesian analysis (Fig. 2) revealed two distinct groups, one including all individuals in the western region (i.e., the Iberian Peninsula and France) and another one including all individuals in the eastern region (i.e., the Italian and Balkan Peninsulas). However, the calculated 65\% PP for the "eastern group" did not provide a significant difference between the two groups. On the other hand, significant differentiation (100\% PP) was found between S. ciliata individuals and the outgroups. Strikingly, two S. ciliata individuals, Pyr1 and Pyr4, were located between the outgroups and the rest of $S$. ciliata, and were significantly different from them as well as from each other. Both Pyr1 and Pyr4 branches were long, implying high substitution rates. One overarching clade was observed (99\% PP) in the "eastern group", and the Din population was the only one branching off this clade. The "western group" consisted of one clade (78 \% PP), but also had many separate individual branches. The maximum likelihood dendrogram obtained with the bootstrapping method did not differ, either in formation or in significance of branches support, from the Bayesian dendrogram.

In the haplotype network approach, the overall analysis (Fig. 3) corroborated the the existence of two (eastern-western) groups and found higher haplotype diversification in 
251 the western group. Of all the eastern populations, the Din haplotype had the nearest 252 position to the western group, which was in agreement with the results obtained from the 253 dendrogram. Sequences assembled into 24 haplotypes, with 12 haplotypes including only 254 western region sequences, 10 haplotypes including only eastern region sequences and two 255 haplotypes outside the network (Pyr1 and Pyr4). Only eastern region sequences Ape1 and 256 Ape2 shared the same haplotype pattern, and no shared haplotype patterns were found 257 between the "eastern" and "western" groups. . Moreover, the haplotype network revealed a 258 close relationship between the haplotype pattern of Ape 3 and some Balkan populations and 259 among the haplotype pattern of Pyr2 and some Central System populations. The $r b c L$ 260 haplotype network (Fig. S1) was selected to visualise the geographic distribution of 261 haplotypes by regions, as it showed the most representative and parsimonious patterns of 262 the three cpDNA regions, when analysed separately (Fig. 5). In that network, Cen2 and 263 Ball haplotypes were prevalent in the western and eastern regions, respectively.

The neighbour-net method suggested a grouping pattern that was in accordance with the one obtained using the haplotype network approach. Besides that, it provided a chance to delve deeper into the differences among $S$. ciliata sampled populations. The allinclusive neighbour-net network (Fig. 4) confirmed the classification of all studied populations into a western and an eastern region, which was $91.6 \%$ statistically supported. Furthermore, some distances inside the network were noteworthy because they verified previous results. This is the case of the observed $98.4 \%$ difference in the distance between Cen1 and the rest of Central System populations (implied by the haplotype network). The Italian Ape 3 showed a minor differentiation (77.1\%) that was also noticed in the haplotype network and in the dendrograms. Last but not least, the eastern population Din was placed in the "western" group.

The Bayesian spatial clustering of populations resulted in an optimal grouping of $K=2$. This supported the western-eastern region division of populations noted in previous analyses. Only the Balkan population Din deviated once more from this division, clustering with the western-region populations. 
283 Genetic diversity in the cpDNA of S. ciliata: a comparative approach

284

285

286

287

288

289

290

291

292

293

294

295

296

297

298

299

300

301

302

303

304

305

306

307

308

309

310

311

312

313

This study reveals high haplotype variability and therefore supports the hypothesis of high cpDNA diversification among S. ciliata populations. Similar results have been reported in previous studies on other Silene species, such as S. latifolia (Ingvarsson \& Taylor, 2002), S. vulgaris (Štorchová \& Olson, 2004) and S. dioica (Hathaway, Malm \& Prentice, 2009), among others. Yet, S. ciliata is ranked among the most varied. Low levels of cpDNA diversification and no diversification at all have been found in S. hifacensis (Prentice et al., 2003) and S. sennenii (López-Vinyallonga et al., 2012), respectively, although this may be due to their narrow distributions and low population sizes (Gitzendanner \& Soltis, 2000; López-Pujol et al., 2009; López-Vinyallonga et al., 2012). Considering this, we suggest that the variation detected in S. ciliata is the outcome of a relatively ancient, wider distribution range, followed by a gradual splintering caused by a series of ice ages, as proposed for many other high-elevation species (reviewed by Nieto Feliner, 2014). An alternative explanation to vicariance is that diversification patterns resulted from dispersal. However, long-distance dispersal events most likely played a minor role given that $S$. ciliata seeds lack any specialized dispersal structure and, thus, most seeds are barochorously dispersed at distances of less than $1 \mathrm{~m}$ (Lara-Romero et al., 2014). Finally, although the step node of the species is dated around 10 million years ago (Sloan et al., 2009), and the diversification of the southern European alpine flora has been correlated with the climatic oscillations of the Pleistocene (Kadereit et al., 2004), we have no information about the date of the crown node. Therefore, we have no evidence of the period when the diversification into the two subspecies took place.

Interpreting the distinction of $S$. ciliata between western and eastern regions and their origin

No evidence was found against the classification of $S$. ciliata into a western and an eastern race (Blackburn, 1933; Tutin et al., 1995). Hence, we propose maintaining the names Silene ciliata subsp. ciliata and S. ciliata subsp. graefferi to describe the noted clustering of $S$. ciliata individuals into a western and eastern group, respectively. On the other hand, 
314 both dendrograms indicated a significant difference between $S$. ciliata individuals and the

315 outgroups which, together with the nonessential divergence between populations,

316 corroborates the monophyly of our species.

317 Tracing back to the species' differentiation, we hypothesize that populations of an

318 ancestor of S. ciliata dominated the Mediterranean Basin. At the onset of glacial period

319 climatic oscillations in the late Tertiary and in the Quaternary period, these ancestral

320 populations might have been forced to migrate to favourable areas, while those unable to

321 encounter a glacial refugium because of distance, time or natural barriers perished. Given

322 that we are dealing with an alpine species, $S$. ciliata populations could have migrated

323 following the paths that constitute links between neighbouring mountains. The Alps

324 mountain range system seems to have posed a persistent and significant hurdle for this

325 species' migration. A rigorous example supporting this theory is that during Quaternary

326 glaciations, the Alps, in contrast to the Mediterranean mountains, were extensively covered

327 with ice sheets (Hughes, Woodward \& Gibbard, 2006; but see Stehlik et al., 2002). This is

328 in accordance with previous phylogeographic studies (e.g. Taberlet et al., 1998; Hewitt,

329 2000) and may explain why S. ciliata populations have not been found there. Moreover, it

330 would account for the observed disconnected distribution and division of the species into

331 the western and eastern groups, since the geographical borders formed by the two groups

332 coincide with the location of the Alps. A similar grouping pattern has been found in the

333 Mediterranean for Androsace vitaliana (Vargas, 2003) and Heliosperma (Frajman \&

334 Oxelman, 2007), genera with the barrier shifting west and east of the Alps region,

335 respectively. Disjunction in distribution, possibly resulting from the Alps and distinction

336 into two subspecies has recently been proposed in Artemisia eriantha, another alpine plant

337 distributed along the Alps and many Mediterranean mountains (Sanz et al., 2014), which

338 also supports our hypothesis.

339

340 Evolutionary processes and geo-climatic effects on western and eastern populations

341

342 Apart from the significant difference found between eastern and western cpDNA

343 sequences, further important diversification was found inside each group. Polyploidization

344 is an evolutionary mechanism that has generated evolutionary lineages during the 
345 Pleistocene (Stebbins, 1984). The number of chromosomes of $S$. ciliata is mostly $\mathrm{n}=24$ or $346 \mathrm{n}=48$, although populations with much higher levels of ploidy have been described in $S$. 347 ciliata subsp. ciliata (Blackburn, 1933; Küpfer, 1974; Tutin et al., 1995). Hence, we 348 propose that this mechanism could explain some of the differentiation within S. ciliata. 349 Nevertheless, considering available chromosome data, we found no relationship between 350 chromosome number and the clustering obtained in our results. Variation may have also resulted from slow mutation events inside disjunct refugia during periods of adverse climatic conditions (Sanz et al., 2014) either as an outcome of elevational range shifts (lowland glacial refugia) or in situ endurance (nunataks). Additionally, other sources of diversification like genetic drift associated to low population sizes and prolonged isolation should be considered (Young, Boyle \& Brown, 1996). mountain range and has led to the genetic disaffiliation of the range into a western and an eastern section. This is in line with the genetic break found in Artemisia eriantha (Sanz et al., 2014). Another component of the western group diversification was introduced by the highly divergent Cen1 sequence of Serra da Estrela, suggesting high isolation of this population. On the other hand, the merging of Pyr2 sequence with Central System S. ciliata individuals may imply braided migrational paths between these populations during glacialinterglacial events.

Interestingly, the degree of divergence recorded in the eastern group of $S$. ciliata is higher than that in the western group. This observation has also been made for temperate trees and shrub taxa (Petit et al., 2003). This higher genetic diversity and the existence of more unique haplotypes, especially in the Balkan Peninsula, might be due to the additional effect of the complex orography and restricted territorial extent of existing refugia, which did not facilitate exchange among populations. More specifically, the various orientations of mountain chains in the Balkans may have acted as a barrier to migration (Tzedakis, 2004). The individuals from the western part of the eastern groups (e.g. Ari and Din) showed some important differences in certain analyses (see Figs 3 and 4). This might be related to the nature of the east Balkan slopes, which have a more gentle relief compared to

374 the steep west mountains (Reed, Kryštufek \& Eastwood, 2004), thereby fostering higher 
376

377

378

379

380

381

382

383

384

385

386

387

388

389

390

391

392

393

394

395

396

397

398

399

400

401

402

403

404

405

406

407

much less affected by glaciations than the rest of the Mediterranean mountain systems (Frajman \& Oxelman, 2007), resulting in the maintenance of relict populations. Lastly, the close relationship of Italian Ape3 with some Balkan populations (especially Bal4) might result from the proposed land connection of the north Italian and Balkan Peninsulas during the early Holocene (approx. 20-16 ka BP) (Lambeck et al., 2004) which would have facilitated dispersal events between the two regions.

\section{The Pyrenees case}

The Bayesian and maximum likelihood analyses showed that Pyr1 and Pyr4 differed from the outgroups as well as from the rest of $S$. ciliata individuals and were situated in an intermediate position between them in the dendrogram (see Fig. 2). Similar results were found in the rest of the analyses. We surmised that this pattern could be another example of the Pyrenees range acting as a stable hybrid zone, as argued in Chorthipopus parallelus (Hewitt, 1993) and Saxifraga subsect. Triplinervium (Mas de Xaxars et al., 2015). At any rate, the rise of hybrid zones due to glaciations, and hence, the preservation of different species genomic information via gene flow (Harrison, 1990) are linked with high altitudes (Hewitt, 2001 and references therein). In the case of Pyr1 and Pyr4, their haplotype patterns may have resulted from chloroplast capture between S. ciliata and other congeneric, sympatric species (Rieseberg \& Soltis, 1991). After all, the geographical contact of congeneric species causing chloroplast sharing has been reported in other studies including species in the same genus, like S. latifolia and S. dioica (Prentice, Malm \& Hathaway, 2008), as well as in other plant groups (e.g. Gardner et al., 2004; Okuyama et al., 2005). Given the number of haplotype patterns detected inside the species, the alternative explanation of Pyr1 and Pyr4 resulting from lineage sorting is another option that cannot be readily rejected (Galtier \& Daubin, 2008).

\section{Conclusions and future prospects}

Our results confirm the monophyly of $S$. ciliata due to the differences found between the studied populations and the outgroups and reveal a clear west-to-east division of S. ciliata 
408

409

410

411

412

413

414

415

416

417

418

419

420

421

422

423

424

425

426

427

428

429

430

431

432

433

434

435

436

437

438

439

populations with the borderline set in the region of the Alps. This division validates the

past classification of the species into two subspecies; $S$. ciliata subsp. ciliata found west of the Alps ("Spanish race", Blackburn, 1933) and S. ciliata subsp. graefferi located east of the Alps ("Italian race", Blackburn, 1933). Major intraspecific variation is supported by all analyses, but none of them supports the occurrence of additional varieties or subspecies (according to Küpfer, 1974 and Castroviejo et al., 1986-2001). In addition, we suggest that geographic and climatic factors may have played a central role in the evolutionary history of the species and the formation of the two subspecies. Further analyses including more individuals and cpDNA markers, as well as mitochondrial DNA (mtDNA) markers and nuclear ribosomal internal transcribed spacer (nrITS) regions, are encouraged to secure conclusions of this role and clarify the status of unsolved-incongruent populations.

Molecular clocks, the inclusion of additional congeneric species and increased sampling effort are necessary to resolve the remaining questions.

\section{Acknowledgements}

We thank the curators of the Muséum National d'Histoire Naturelle (Paris, France), the Natural History Museum (Florence, Italy), Herbarium Apenninicum (Parco Nazionale del Gran Sasso e Monti della Laga, Italy), Herbario de Jaca (Huesca, Spain), Sofia Herbarium (Bulgaria), Herbarium of the Botanical Institute of the University of Patra (Patra, Greece), Herbario de la Universidad de Barcelona, (Barcelona, Spain) and Herbario del Real Jardín Botanico (Madrid, Spain) for the loan of Silene ciliata material. We would also like to thank Panayiotis Trigas, Angela López, Marcos Méndez, Luis Giménez-Benavides, Rubén Milla and Alvaro Bueno for plant collection and Lori De Hond for linguistic assistance.

\section{References}

Abbott RJ, Chapman HM, Crawford RMM, Forbes DG. 1995. Molecular diversity and derivations of populations of Silene acaulis and Saxifraga oppositifolia from the high Arctic and more southerly latitudes. Molecular Ecology, 4:199-208

Brotero FA. 1804. Flora Lusitánica. Olisipone: Ex Typographia Regia Bari EA. 1973. Cytological Studies in the Genus Silene L. New Phytologist, 72:833-838 
440 Bernasconi G, Antonovics J, Biere A, Charlesworth D, Delph LF, Filatov D, Widmer A.

441 2009. Silene as a model system in ecology and evolution. Heredity, 103:5-14

442 Blackburn KB. 1933. On the relation between geographic races and polyploidy in Silene

443 ciliata Pourr. Genetica, 15:49-66

444 Castroviejo S, Aedo C, Cirujano S, Laínz M, Montserrat P, Morales R, Muñoz Garmendia

445 F, Navarro C, Paiva J, Soriano C. 1986-2001. Flora Ibérica. Plantas vasculares de la

446 Península Ibérica e Islas Baleares. Madrid: Real Jardín Botánico, CSIC

447 Clement M, Posada D, Crandall KA. 2000. TCS: a computer program to estimate gene

448 genealogies. Molecular Ecology, 9:1657-1659

449 Corander J, Marttinen P, Sirén J, Tang J. 2008. Enhanced Bayesian modelling in BAPS

450 software for learning genetic structures of populations. BMC Bioinformatics, 9:539

451 Frajman B, Oxelman B. 2007. Reticulate phylogenetics and phytogeographical structure of

452 Heliosperma (Sileneae, Caryophyllaceae) inferred from chloroplast and nuclear DNA

453 sequences. Molecular Phylogenetics and Evolution, 43:140-155

454 Galtier N, Daubin V. 2008. Dealing with incongruence in phylogenomic analyses.

455 Philosophical Transactions of the Royal Society B: Biological Sciences, 363:4023-4029

456 Gardner RC, de Lange PJ, Peter J, Keeling DJ, Bowala T, Brown HA, Wright SD. 2004. A

457 late Quaternary phylogeography for Metrosideros (Myrtaceae) in New Zealand inferred

458 from chloroplast DNA haplotypes. Biological Journal of the Linnean Society, 83:399-412

459 Giménez-Benavides L, Escudero A, Iriondo JM. 2007. Reproductive limits of a late-

460 flowering high mountain Mediterranean plant along an elevational climate gradient. New

461 Phytologist, 173:367-382

462 Gitzendanner MA, Soltis PS. 2000. Patterns of genetic variation in rare and widespread

463 plant congeners. American Journal of Botany, 87:783-792

464 Greenberg AK, Donoghue MJ. 2011. Molecular systematics and character evolution in

465 Caryophyllaceae. Taxon, 60:1637-1652

466 Greuter W. 1995. Silene (Caryophyllaceae) in Greece: a subgeneric and sectional

467 classification. Taxon, 44:543-581

468 Guindon S, Dufayard JF, Lefort V, Anisimova M, Hordijk W, Gascuel O. 2010. New

469 algorithms and methods to estimate maximum-likelihood phylogenies: assessing the

470 performance of PhyML 3.0. Systematic Biology, 59:307-321 
471 Hall TA. 1999. BioEdit: A user-friendly biological sequence alignment editor and analysis

472 program for Windows 95/98/NT. Nuclear Acids Symposium Series, 41:95-98

473 Harrison RG. 1990. Hybrid zones: windows on evolutionary process. Oxford Surveys in

474 Evolutionary Biology, 7:69-128

475 Hathaway L, Malm JU, Prentice HC. 2009. Geographically congruent large-scale patterns

476 of plastid haplotype variation in the European herbs Silene dioica and S. latifolia

477 (Caryophyllaceae). Botanical Journal of the Linnean Society, 161:153-170

478 Heuertz M, Fineschi S, Anzidei M, Pastorelli R, Salvini D, Paule L, Frascaria-Lacoste N,

479 Hardy OJ, Vekemans X, Vendramin GG. 2004. Chloroplast DNA variation and postglacial

480 recolonization of common ash (Fraxinus excelsior L.) in Europe. Molecular Ecology,

$481 \quad 13: 3437-3452$

482 Hewitt GM. 1993. After the ice: Parallelus meets Erythropus in the Pyrenees. In: Harrison

483 RG, ed. Hybrid zones and the evolutionary process. Oxford: Oxford University Press, 140$484 \quad 164$

485 Hewitt GM. 2000. The genetic legacy of the Quaternary ice ages. Nature, 405:907-913

486 Hewitt GM. 2001. Speciation, hybrid zones and phylogeography- or seeing genes in space

487 and time. Molecular Ecology, 10:537-549

488 Hewitt GM. 2004. Genetic consequences of climatic oscillations in the Quaternary.

489 Philosophical Transactions of the Royal Society of London. Series B: Biological Sciences, 490 359:183-195

491 Huelsenbeck JP, Ronquist F, Nielsen R, Bollback JP. 2001. Bayesian inference of

492 phylogeny and its impact on evolutionary biology. Science, 294:2310-2314

493 Hughes PD, Woodward JC, Gibbard PL. 2006. Quaternary glacial history of the

494 Mediterranean mountains. Progress in Physical Geography, 30:334-364

495 Huson DH, Bryant D. 2006. Application of phylogenetic networks in evolutionary studies.

496 Molecular Biology and Evolution, 23:254-267

497 Ingvarsson PK, Taylor DR. 2002. Genealogical evidence for epidemics of selfish genes.

498 Proceedings of the National Academy of Sciences, 99:11265-11269

499 Irwin DE. 2002. Phylogeographic breaks without geographic barriers to gene flow.

500 Evolution, 56:2383-2394 
501

502

503

504

505

506

507

508

509

510

511

512

513

514

515

516

517

518

519

520

521

522

523

524

525

526

527

528

529

530

Jalas J, Suominen J. 1988. Atlas Florae Europaeae: distribution of vascular plants in Europe. Cambridge: Cambridge University Press

Kadereit JW, Griebeler EM, Comes HP. 2004. Quaternary diversification in European alpine plants: pattern and process. Philosophical Transactions of the Royal Society B:

Biological Sciences, 359:265-274

Körner C. 2003. Alpine plant life: functional plant ecology of high mountain ecosystems; with 47 tables. New York: Springer Science+Business Media

Küpfer P. 1974. Recherches sur les liens de parenté entre la flore orophile des Alpes et celle des Pyrénées. Boissiera, 23:113-131

Lambeck K, Antonioli F, Purcell A, Silenzi S. 2004. Sea-level change along the Italian coast for the past 10,000 yr. Quaternary Science Reviews, 23:1567-1598

Lara-Romero C, Robledo-Arnuncio JJ, García-Fernández A, Iriondo JM. 2014. Assessing intraspecific variation in effective dispersal along an altitudinal gradient: a test in two Mediterranean high-mountain plants. PloS one, 9.1.

Lewis WH. 1980. Polyploidy in species populations. In: Lewis W, ed. Polyploidy. New York: Springer US, 103-144

Librado P, Rozas J. 2009. DnaSP v5: a software for comprehensive analysis of DNA polymorphism data. Bioinformatics, 25:1451-1452

López-Pujol J, Bosch M, Simon J, Blanché C. 2009. Patterns of genetic diversity in the highly threatened vascular flora of the Mediterranean Basin. In: Columbus A; Kuznetsov L, eds. Endangered species: new research. New York: Nova Science Publishers, 45-79 López-Vinyallonga S, López-Pujol J, Martinell MC, Massó S, Blanché C. 2012. Genetic diversity in Silene sennenii Pau (Caryophyllaceae) assayed through DNA-based techniques. Collectanea Botanica, 31:7-18

Mas de Xaxars G, García-Fernández A, Barnola P, Martín J, Mercadé A, Vallés J, Vargas P, Vigo J, Garnatje T. 2015. Phylogenetic and cytogenetic studies reveal hybrid speciation in Saxifraga subsect. Triplinervium (Saxifragaceae). Journal of Systematics and Evolution, 53:53-62

McCauley DE. 1997. The relative contributions of seed and pollen movement to the local genetic structure of Silene alba. Heredity, 88:257-263 
531 Médail F, Diadema K. 2009. Glacial refugia influence plant diversity patterns in the

532 Mediterranean Basin. Journal of Biogeography, 36:1333-1345

533 Nieto Feliner G. 1985. Estudio Crítico de la Flora Orófila del Suroeste de León: Montes

534 Achilianos, Sierra del Teleno y Sierra de la Cabrera. Madrid: Real Jardín Botánico, CSIC

535 Nieto Feliner G. 2014. Patterns and processes in plant phylogeography in the

536 Mediterranean Basin. A review. Perspectives in Plant Ecology, Evolution and Systematics, $537 \quad 16: 265-278$

538 Okuyama Y, Fujii N, Wakabayashi M, Kawakita A, Ito M, Watanabe M, Murakami N, 539 Makoto K. 2005. Nonuniform concerted evolution and chloroplast capture: heterogeneity 540 of observed introgression patterns in three molecular data partition phylogenies of Asian

541 Mitella (Saxifragaceae). Molecular Biology and Evolution, 22:285-296

542 Oxelman B, Lidén M, Rabeler RK, Popp M. 2000. A revised generic classification of the 543 tribe Sileneae (Caryophyllaceae). Nordic Journal of Botany, 20:743-748

544 Pawłowski B. 1970. Remarques sur l'endémisme dans la flore des Alpes et des Carpates.

545 Vegetatio, 21:181-243

546 Petit RJ, Aguinagalde I, de Beaulieu JL, Bittkau C, Brewer S, Cheddadi R, Ennos R, 547 Fineschi S, Grivet D, Lascoux M, Mohanty A, Müller-Starck G, Demesure-Musch B, 548 Palmé A, Martín JP, Rendell S, Vendramin GG. 2003. Glacial refugia: hotspots but not 549 melting pots of genetic diversity. Science, 300:1563-1565

550 Petit RJ, Kremer A, Wagner DB. 1993. Finite island model for organelle and nuclear genes 551 in plants. Heredity, 71:630-641

552 Popp M, Erixon P, Eggens F, Oxelman B. 2005. Origin and evolution of a circumpolar 553 polyploid species complex in Silene (Caryophyllaceae) inferred from low copy nuclear 554 RNA polymerase introns, rDNA, and chloroplast DNA. Systematic Botany, 30:302-313 555 Posada D. 2008. jModelTest: Phylogenetic model averaging. Molecular Biology and 556 Evolution, 25:1253-1256

557 Prentice HC, Malm JU, Hathaway L. 2008. Chloroplast DNA variation in the European 558 herb Silene dioica (red campion): postglacial migration and interspecific introgression. 559 Plant Systematics and Evolution, 272:23-37 
560 Prentice HC, Malm JU, Mateu-Andrés I, Segarra-Moragues JG. 2003. Allozyme and

561 chloroplast DNA variation in island and mainland populations of the rare Spanish endemic,

562 Silene hifacensis (Caryophyllaceae). Conservation Genetics, 4:543-555

563 Quinn JF, Harrison SP. 1988. Effects of habitat fragmentation and isolation on species

564 richness: evidence from biogeographic patterns. Oecologia, 75:132-140

565 Rambaut A. 2006. FigTree 1.3.1. Edinburgh: Edinburgh University Press

566 Rautenberg A, Filatov D, Svennblad B, Heidari N, Oxelman B. 2008. Conflicting

567 phylogenetic signals in the S1X1/Y1 gene in Silene. BMC Evolutionary Biology, 8:299

568 Rautenberg A, Hathaway L, Oxelman B, Prentice HC. 2010. Geographic and phylogenetic

569 patterns in Silene section Melandrium (Caryophyllaceae) as inferred from chloroplast and

570 nuclear DNA sequences. Molecular Phylogenetics and Evolution, 57:978-991

571 Reed JM, Kryštufek B, Eastwood WJ. 2004. The physical geography of the Balkans and

572 nomenclature of place names. In: Griffiths HI; Kryštufek B; Reed JM, eds. Balkan

573 Biodiversity: Pattern and Process in the European Hotspot. Dordrecht: Springer

574 Netherlands, 9-22

575 Rieseberg LH, Soltis DE. 1991. Phylogenetic consequences of cytoplasmic gene flow in

576 plants. Evolutionary Trends in Plants, 5:65-84

577 Sanz M, Schönswetter P, Vallés J, Schneeweiss GM, Vilatersana R. 2014. Southern

578 isolation and northern long-distance dispersal shaped the phylogeography of the

579 widespread, but highly disjunct, European high mountain plant Artemisia eriantha

580 (Asteraceae). Botanical Journal of the Linnean Society, 174:214-226

581 Schönswetter P, Stehlik I, Holderegger R, Tribsch A. 2005. Molecular evidence for glacial

582 refugia of mountain plants in the European Alps. Molecular Ecology, 14:3547-3555

583 Shaw J, Lickey EB, Beck JT, Farmer SB, Liu W, Miller J, Siripun KC, Winder CT,

584 Schilling EE, Small RL. 2005. The tortoise and the hare II: relative utility of 21 noncoding

585 chloroplast DNA sequences for phylogenetic analysis. American Journal of Botany,

586 92:142-166

587 Shaw J, Lickey EB, Schilling EE, Small RL. 2007. Comparison of whole chloroplast

588 genome sequences to choose noncoding regions for phylogenetic studies in angiosperms:

589 the tortoise and the hare III. American Journal of Botany, 94:275-288 
590 Sloan DB, Oxelman B, Rautenberg A, Taylor DR. 2009. Phylogenetic analysis of

591 mitochondrial substitution rate variation in the angiosperm tribe Sileneae. BMC

592 Evolutionary Biology, 9:260-275

593 Stebbins GL. 1984. Polyploidy and the distribution of the arctic-alpine flora: new evidence

594 and a new approach. Botanica Helvetica, 94:1-13

595 Stehlik I, Blattner FR, Holderegger R, Bachmann K. 2002. Nunatak survival of the high

596 Alpine plant Eritrichium nanum (L.) Gaudin in the central Alps during the ice ages.

597 Molecular Ecology, 11:2027-2036

598 Štorchová H, Olson MS. 2004. Comparison between mitochondrial and chloroplast DNA

599 variation in the native range of Silene vulgaris. Molecular Ecology, 13:2909-2919

600 Strid A, Tan K. 2002. Flora Hellenica. Königstein: Koeltz Scientific Books

601 Taberlet P, Fumagalli L, Wust-Saucy AG, Cosson JF. 1998. Comparative phylogeography

602 and postglacial colonization routes in Europe. Molecular Ecology, 7:453-464

603 Thompson JD, Higgins DG, Gibson JJ. 1994. CLUSTAL W: improving the sensitivity of

604 progressive multiple alignment through sequence weighting, position-specific gap penalties

605 and weight matrix choice. Nucleic Acids Research, 22:4673-4680

606 Tutin TG, Heywood VH, Burges NA, Valentine DH, Walters SM, Webb DA. 1995. Flora

607 Europaea. Cambridge: Cambridge University Press

608 Tzedakis PC. 2004. The Balkans as prime glacial refugial territory of European temperate

609 trees. In: Griffiths HI; Kryštufek B; Reed JM, eds. Balkan Biodiversity: Pattern and

610 Process in the European Hotspot. Dordrecht: Springer Netherlands, 49-65

611 Tzedakis PC, Lawson IT, Frogley MR, Hewitt GM, Preece RC. 2002. Buffered tree

612 population changes in a Quaternary refugium: evolutionary implications. Science,

$613 \quad 297: 2044-2047$

614 Vargas P. 2003. Molecular evidence for multiple diversification patterns of alpine plants in

615 Mediterranean Europe. Taxon, 52:463-476

616 Wiens JJ. 2004. Speciation and ecology revisited: phylogenetic niche conservatism and the

617 origin of species. Evolution, 58:193-197

618 Young A, Boyle T, Brown T. 1996. The population genetic consequences of habitat

619 fragmentation for plants. Trends in Ecology \& Evolution, 11:413-418

620 Zángheri P, Brilli-Cattarini AJ. 1976. Flora Italica. Padova: Cedam 


\section{Table $\mathbf{1}$ (on next page)}

Details of the sampled populations of Silene ciliata

DNA samples of Silene ciliata used for the study. The table shows the acronym given to each sampled population («Name»), the «Country» where these populations were collected, «Altitude» and MGRS coordinates. A more detailed version of this table can be found in Table S1. 


\begin{tabular}{|c|c|c|c|}
\hline Name & Country & Altitude(m) & MGRS \\
\hline Can1 & $\mathrm{ES}$ & 1642 & 29TQH4477 \\
\hline Can2 & $\mathrm{ES}$ & 1900 & 30TUN3712 \\
\hline Can3 & $\mathrm{ES}$ & 1881 & 30TUN5150 \\
\hline Ibe1 & $\mathrm{ES}$ & 1900 & 30TVM9646 \\
\hline Ibe2 & $\mathrm{ES}$ & 2278 & 30TWM0276 \\
\hline Pyr1 & ES & 1931 & 30TYN2920 \\
\hline Pyr2 & ES & $1350-1780$ & 30TYN4026 \\
\hline Pyr3 & ES & $2100-2200$ & $31 \mathrm{~T} \mathrm{CG7967}$ \\
\hline Pyr5 & ES & 2161 & 31 TDG1980 \\
\hline Cen2 & ES & 1950 & 30TTK7079 \\
\hline Cen 3 & $\mathrm{ES}$ & 2340 & 30TVL2104 \\
\hline Cen 1 & POR & 1900 & 29TPE1783 \\
\hline Mas & FR & 1560 & 31 TDL8119 \\
\hline Pyr4 & FR & 2190 & 31TDH3461 \\
\hline Ari & GR & 2182 & 34TFL0142 \\
\hline Bal3 & GR & 1800 & 35 TKF5580 \\
\hline Bal4 & GR & 1800 & 35TKF5307 \\
\hline Bal5 & GR & 1800 & 35 TKF5586 \\
\hline Bal6 & GR & 2060 & 35 TKF5632 \\
\hline Bal1 & $\mathrm{BU}$ & 1900 & 34TGM0365 \\
\hline Bal2 & $\mathrm{BU}$ & 2600 & 34TGM0229 \\
\hline Din & MAC & 2480 & 34TEM2771 \\
\hline Ape1 & IT & 1950 & 33TUH8528 \\
\hline Ape2 & IT & 1366 & 33TUH7979 \\
\hline Ape3 & IT & 2000 & 33 TVG2225 \\
\hline
\end{tabular}

3 


\section{Table 2 (on next page)}

Characteristics of the polymorphic cpDNA regions

Characteristics of the three polymorphic cpDNA regions and the "all-marker" region studied in Silene ciliata. The length of the products after amplification with the corresponding marker and alignment editing, and the variable and parsimony sites of each product ensued from the DnaSP analysis are shown. 


\begin{tabular}{|c|c|c|c|}
\hline Chloroplast marker & $\begin{array}{l}\text { Length of selected } \\
\text { region }\end{array}$ & $\begin{array}{c}\text { Variable } \\
\text { (polymorphic) } \\
\text { sites }\end{array}$ & $\begin{array}{c}\text { Parsimony } \\
\text { informative sites }\end{array}$ \\
\hline$r b c L$ & $564 \mathrm{bp}$ & 4 & 3 \\
\hline rps 16 & $753 \mathrm{bp}$ & 25 & 16 \\
\hline $\operatorname{trn} L$ & $513 \mathrm{bp}$ & 18 & 11 \\
\hline all & $1830 \mathrm{bp}$ & 47 & 30 \\
\hline
\end{tabular}




\section{1}

Figure1: Map of our sampled populations of Silene ciliata

Distribution of sampled S. ciliata populations in the Mediterranean Basin. Acronyms were derived from the name of the mountain system where samples were collected: Can Cantabrian Range, Ibe - Iberian System, Pyr - Pyrenees range, Cen - Central System, Mas Central Massif, Ari - Aridaia range, Bal - Balkan-Rhodope mountain system, Din - Dinaric Alps and Ape - Apennines range.

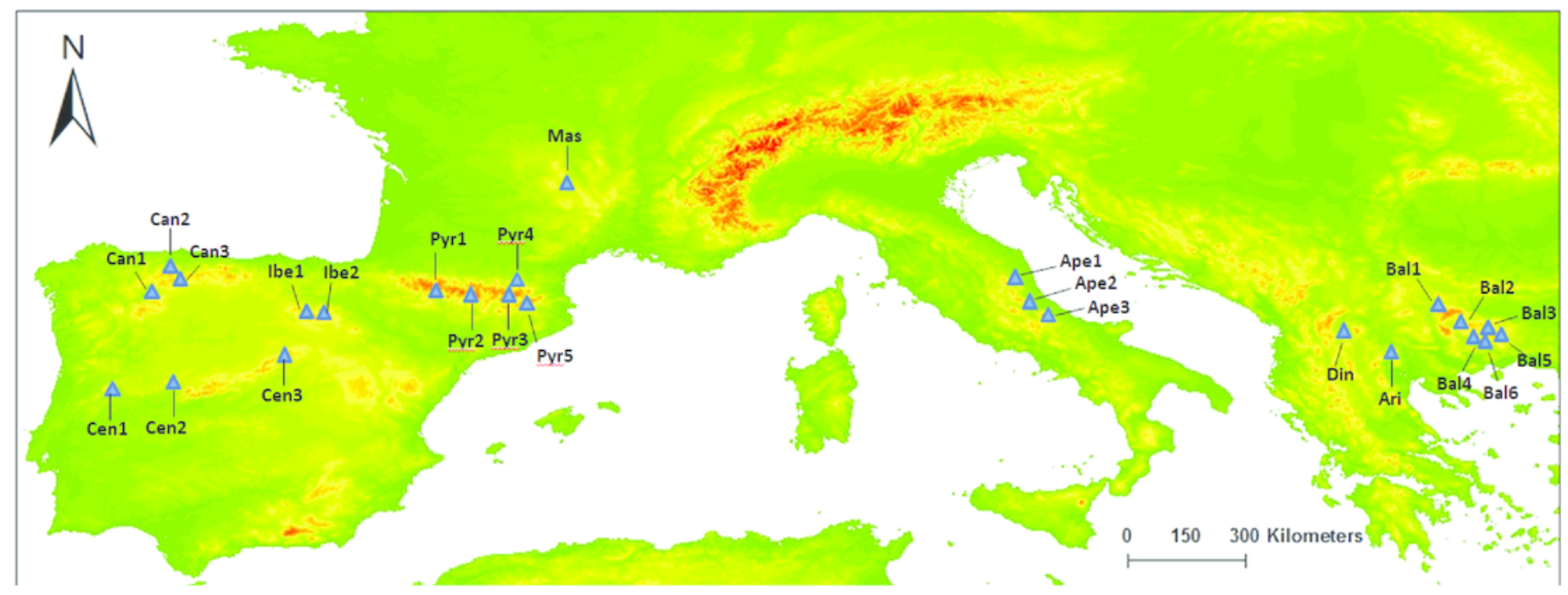


2

Figure 2: Bayesian dendrogram

Bayesian consensus dendrogram of the "all-marker" cpDNA sequence of Silene ciliata.

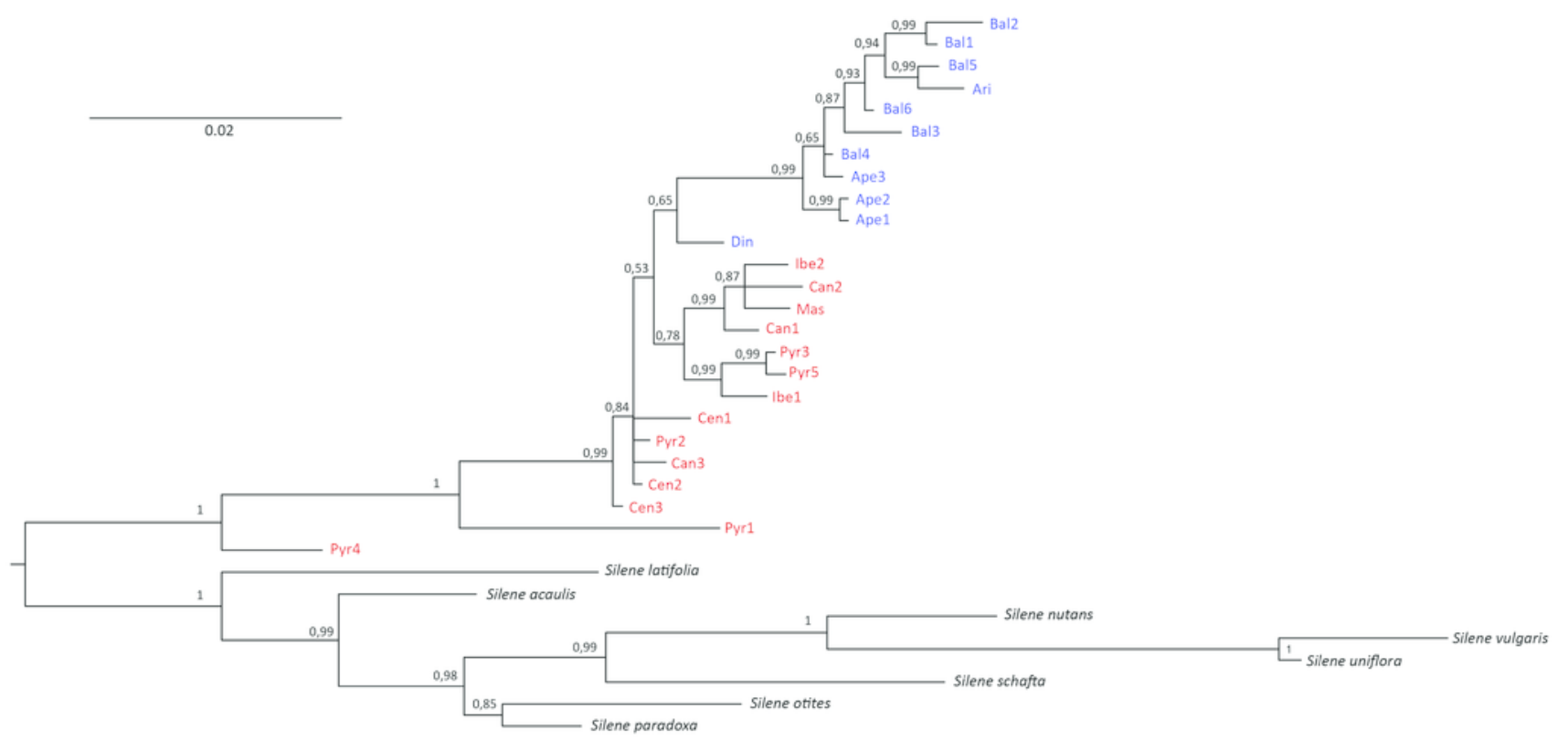


3

Total cpDNA haplotype network

Combined haplotype network analysis including all cpDNA markers and showing the relationships between the cpDNA parsimony haplotype groups. Rectangles and ovals depict haplotypes that belong to the western and eastern groups, respectively. The patterns of individuals Pyr1 and Pyr4 are segregating from the rest of the haplotypes. 


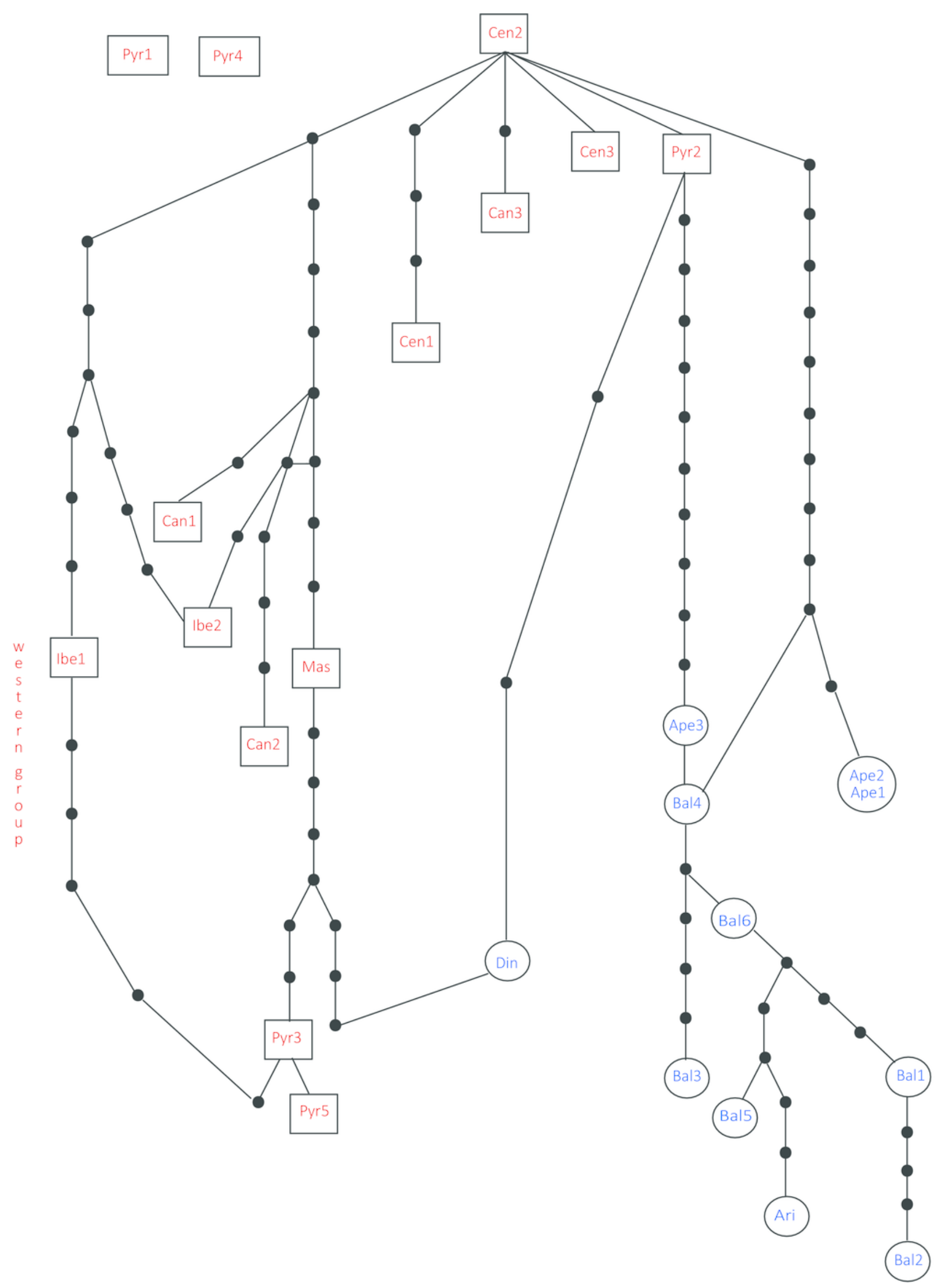


4

Neighbour-net analyses of the total matrix.

Neighbour-net analyses of $r b c L(a), \operatorname{rps} 16(b)$ and $\operatorname{trnL}(c)$ based on uncorrected p-distances.

Numbers denote significant bootstrapping values. The eastern and western groups of $\mathrm{S}$.

ciliata populations are indicated by grey-shaded clusters. Blue letters correspond to the eastern group and red letters to the western group.

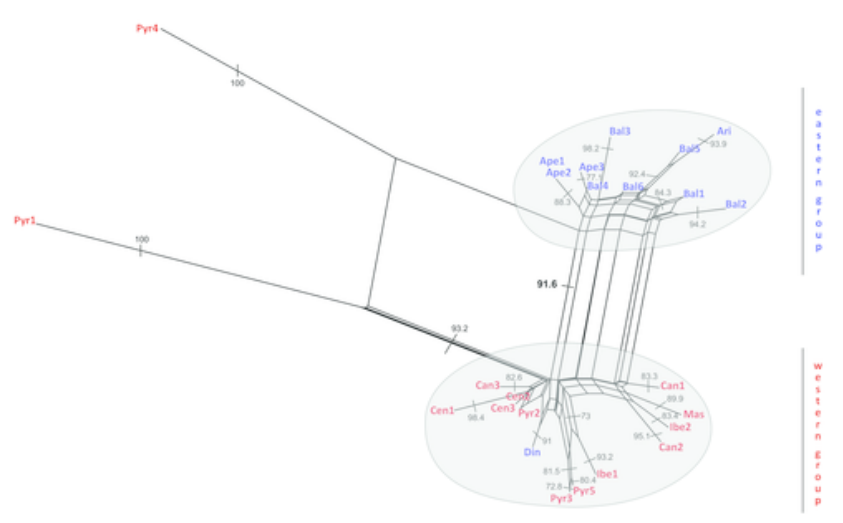




\section{5}

Figure 5: Distribution and frequency ratios of $r b c L$ haplotypes

Distribution and frequency ratios of S. ciliata haplotypes for rbcL (see Fig. 4a) in the mountain systems of this study. The proportion of different haplotypes at each location is shown in the circles.

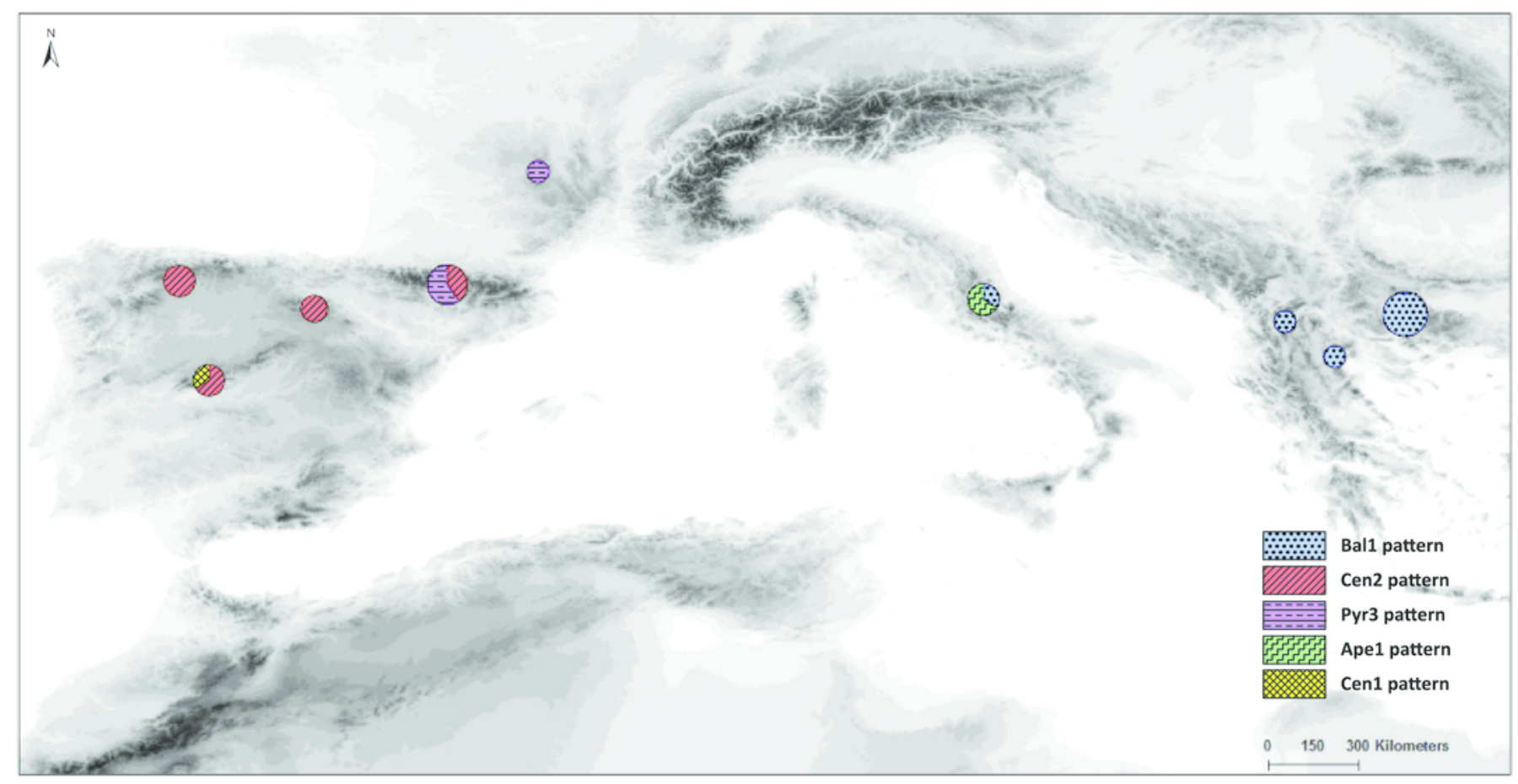

